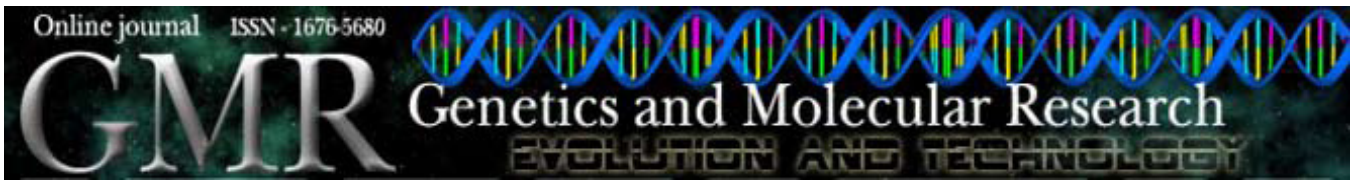

\title{
Gender identification of five genera of stingless bees (Apidae, Meliponini) based on wing morphology
}

\author{
T.M. Francoy ${ }^{1}$, R.A.O. Silva ${ }^{1}$, P. Nunes-Silva ${ }^{1}$, C. Menezes $^{1}$ \\ and V.L. Imperatriz-Fonseca ${ }^{1,2}$ \\ ${ }^{1}$ Faculdade de Filosofia, Ciências e Letras de Ribeirão Preto, \\ Universidade de São Paulo, Ribeirão Preto, SP, Brasil \\ ${ }^{2}$ Instituto de Biociências, Universidade de São Paulo, São Paulo, SP, Brasil \\ Corresponding author: T.M. Francoy \\ E-mail: tfrancoy@rge.fmrp.usp.br
}

Genet. Mol. Res. 8 (1): 207-214 (2009)

Received November 26, 2007

Accepted November 27, 2008

Published February 25, 2009

\begin{abstract}
Currently, the identification of pollinators is a critical necessity of conservation programs. After it was found that features extracted from patterns of wing venation are sufficient to discriminate among insect species, various studies have focused on this structure. We examined wing venation patterns of males and workers of five stingless bee species in order to determine if there are differences between sexes and if these differences are greater within than between species. Geometric morphometric analyses were made of the forewings of males and workers of Nannotrigona testaceicornis, Melipona quadrifasciata, Frieseomelitta varia, and Scaptotrigona aff. depilis and Plebeia remota. The patterns of males and workers from the same species were more similar than the patterns of individuals of the same sex from different species, and the patterns of both males and workers, when analyzed alone, were sufficiently different to distinguish among these five species. This demonstrates that we can use this kind of analysis for the identification of stingless bee species and that the sex of the individual does not impede identification. Computer-assisted morphometric analysis of
\end{abstract}


bee wing images can be a useful tool for biodiversity studies and conservation programs.

Key words: Meliponini; Wing morphometry; Conservation; Geometric morphometry: Sex differentiation; Species identification

\section{INTRODUCTION}

Due to the recent decline of pollinators in natural areas (Biesmeijer et al., 2006), the development of tools that facilitate the identification of species in the field is of extreme importance for evaluating biodiversity. It has been demonstrated that insect species can be identified based on wing morphology alone; several studies have focused on using this type of information to discriminate intraspecific groups, such as populations and subspecies, with very good results (Gaston and O’Neill, 2004; Tofilski, 2004; Steinhage et al., 2007). Wing morphology analysis has given very good identification rates in bees (Schröder et al., 1995; Steinhage et al., 2001; Drauschke et al., 2007; Mendes et al., 2007; Francoy et al., 2006, 2008).

A new methodology that has recently been applied to the identification of stingless bees is geometric morphometric analysis of the forewings. It has been used to resolve taxonomic problems in bumble bees (Aytekin et al., 2007) and also to identify honey bee subspecies, and to examine changes in the morphometric profile of some Africanized honey bee populations over time (Francoy et al., 2009). In the first research project applying these techniques to the Meliponini, relative warp analysis of the forewings, confirmed by other techniques, showed no gene flow between two populations of Plebeia remota collected from various regions of Brazil and maintained in the same area for several years (Francisco et al., 2008). Relative warp analysis of the forewings was also found to be efficient for differentiating sub-populations of Nannotrigona testaceicornis from a single locality, attaining $74 \%$ accuracy in identifying these sub-populations (Mendes et al., 2007).

Generally, automatic species recognition softwares that are based on wing morphology, such as ABIS (Schröder et al., 1995), do not take into consideration the sex of the individuals. Stingless bees have as a synapomorphy, reductions in wing venation. It is also known that males and workers have different behaviors and flight activities during their lifespan. This could lead to differentiation in the patterns of wing venation and could confuse automated software analysis. We examined the morphology of the forewing of males and females of five different stingless bee species to determine if this type of information is sufficient to discriminate species and sexes within a species.

\section{MATERIAL AND METHODS}

Samples of Nannotrigona testaceicornis, Melipona quadrifasciata, Frieseomelitta varia, and Scaptotrigona aff. depilis were collected from the meliponary of the campus of the University of São Paulo in Ribeirão Preto $\left(21^{\circ} 10^{\prime} \mathrm{S} 47^{\circ} 48^{\prime} \mathrm{W}\right)$ and a sample of Plebeia remota was collected from the São Paulo campus of the same university ( $23^{\circ} 32^{\prime} \mathrm{S} 46^{\circ} 38^{\prime}$ ). We collected 10 males and 10 workers from each of two colonies of the five species, for a total of 100 males and 100 workers per species. In the case of Melipona quadrifasciata, we also 
collected 87 males from the front of a hive and males of Nannotrigona testaceicornis were collected from a cloud of males in front of a colony. The right wings were mounted between microscope slides and photographed with a digital camera attached to a stereomicroscope. Visually, the wings of males and females of these species are indistinguishable. Eleven landmarks were plotted at the junctions of the wing venation (Figure 1) using the tpsDig2 version 2.04 software (Rolhf, 2005a). The Cartesian coordinates of the landmarks were then aligned and a partial warps analysis was done using the tpsRelw version 1.42 software (Rolhf, 2005b). All softwares are freely available from the internet (http://life.bio.sunysb.edu/morph/).

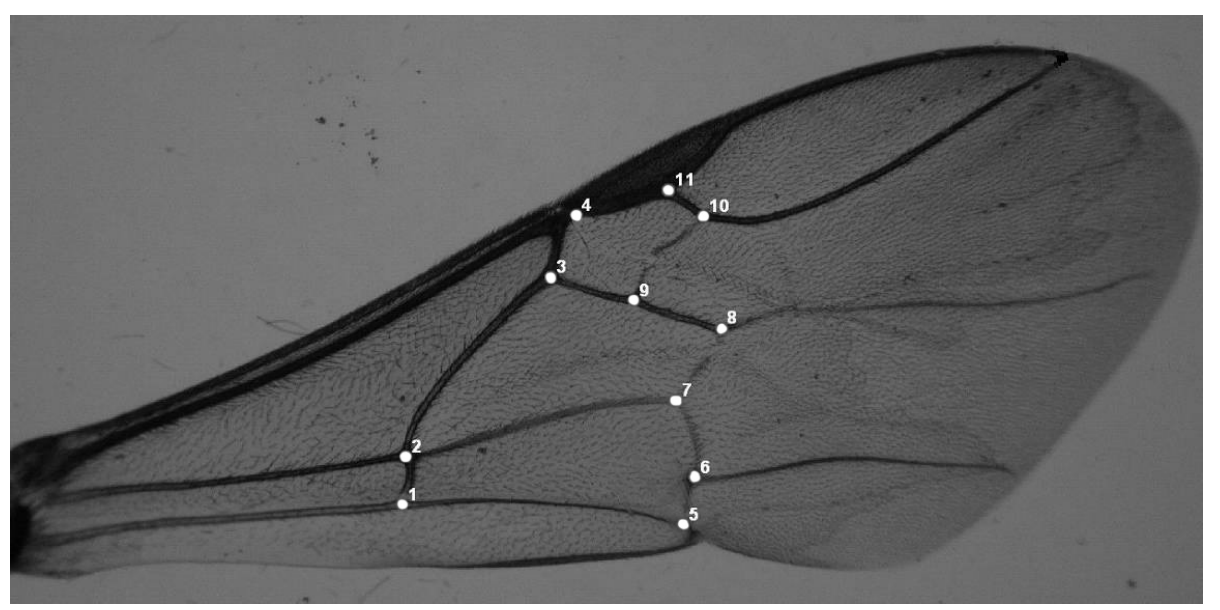

Figure 1. Right forewing of a worker of Plebeia remota. The white circles indicate the respective position of each of the plotted landmarks.

We conducted a principal component analysis (PCA) of the Cartesian coordinates of the males and workers of the five species. We also carried out a forward stepwise analysis (tolerance $0.01 ; \mathrm{F}$ to enter 1.00 ) to determine classification functions, followed by a canonical analysis and then a cross validation test to check the accuracy of the equations in identifying the colonies. In the cross validation, each case was classified by the functions derived from all cases other than that case. Though it is less powerful, the cross validation test gives a more realistic and unbiased classification. After extraction of the measures, all statistical analyses were performed using Statistica 6.0 (StatSoft, 2001).

\section{RESULTS}

The PCA of the Cartesian coordinates extracted from the wings of males and workers of the five species gave three eigenvalues greater than one, which explained $81.34 \%$ of the variation among the groups. The variable $6 \mathrm{X}$ was the one that influenced the first factor most; alone, it explained $47.91 \%$ of the variability among the groups. Variable $10 \mathrm{X}$ influenced the second factor most; it explained $24.24 \%$ of the variability. The mean configurations of the landmark positions of each of the groups can be found in Table 1. 
Table 1. Mean configuration of the 11 landmarks plotted of the sexes of the stingless bee species Nannotrigona testaceicornis, Melipona quadrifasciata, Frieseomelitta varia, and Scaptotrigona aff. depilis and Plebeia remota.

\begin{tabular}{|c|c|c|c|c|c|c|c|c|c|c|}
\hline & \multicolumn{2}{|c|}{ P. remota } & \multicolumn{2}{|c|}{ S. depilis } & \multicolumn{2}{|c|}{ N. testaceicornis } & \multicolumn{2}{|c|}{ M. quadrifasciata } & \multicolumn{2}{|c|}{ F. varia } \\
\hline & worker & male & worker & male & worker & male & worker & male & worker & male \\
\hline $1 \mathrm{X}$ & -0.45512 & -0.45744 & -0.44795 & -0.45035 & -0.44994 & -0.4486 & -0.47009 & -0.46476 & -0.46226 & -0.46425 \\
\hline $1 \mathrm{Y}$ & -0.12326 & -0.12114 & -0.1554 & -0.15198 & -0.13016 & -0.13128 & -0.17694 & -0.17227 & -0.12885 & -0.12416 \\
\hline $2 \mathrm{X}$ & -0.42356 & -0.41989 & -0.44897 & -0.43409 & -0.43308 & -0.42881 & -0.43838 & -0.43006 & -0.44562 & -0.44319 \\
\hline $2 \mathrm{Y}$ & -0.03846 & -0.0444 & -0.05205 & -0.05202 & -0.04173 & -0.04093 & -0.07288 & -0.06376 & -0.05674 & -0.05428 \\
\hline $3 \mathrm{X}$ & -0.06129 & -0.06377 & -0.01317 & -0.02246 & -0.04735 & -0.05254 & -0.01441 & -0.02034 & -0.04293 & -0.04944 \\
\hline $3 Y$ & 0.1774 & 0.18164 & 0.17274 & 0.17694 & 0.16597 & 0.17276 & 0.15448 & 0.16041 & 0.18363 & 0.18684 \\
\hline $4 X$ & 0.03415 & 0.02406 & 0.08203 & 0.0698 & 0.05469 & 0.04324 & 0.08069 & 0.0686 & 0.01931 & 0.00906 \\
\hline $4 \mathrm{Y}$ & 0.26638 & 0.26891 & 0.25642 & 0.26004 & 0.26296 & 0.26705 & 0.23692 & 0.24072 & 0.23901 & 0.24231 \\
\hline $5 X$ & 0.0169 & 0.01284 & 0.00605 & 0.00108 & 0.01975 & 0.01018 & -0.01094 & -0.01641 & -0.00361 & 0.00236 \\
\hline $5 \mathrm{Y}$ & -0.36556 & -0.36566 & -0.35566 & -0.36438 & -0.35847 & -0.35912 & -0.34483 & -0.3549 & -0.33367 & -0.33917 \\
\hline $6 \mathrm{X}$ & 0.05663 & 0.05303 & 0.02264 & 0.02025 & 0.04863 & 0.04335 & -0.02133 & -0.01422 & 0.04758 & 0.0504 \\
\hline $6 \mathrm{Y}$ & -0.2728 & -0.27176 & -0.25305 & -0.25802 & -0.27746 & -0.27744 & -0.23557 & -0.24184 & -0.25101 & -0.2516 \\
\hline $7 X$ & 0.06969 & 0.07892 & 0.05602 & 0.06366 & 0.06456 & 0.07751 & 0.03765 & 0.04963 & 0.08943 & 0.09463 \\
\hline $7 Y$ & -0.12132 & -0.11512 & -0.11985 & -0.11368 & -0.1228 & -0.12196 & -0.09059 & -0.09094 & -0.10798 & -0.1032 \\
\hline $8 X$ & 0.18022 & 0.18529 & 0.18153 & 0.18351 & 0.15852 & 0.17206 & 0.21799 & 0.2201 & 0.20162 & 0.20176 \\
\hline $8 Y$ & -0.02151 & -0.02404 & -0.02407 & -0.02374 & -0.01971 & -0.02667 & 0.00607 & -0.00304 & -0.04094 & -0.04379 \\
\hline $9 \mathrm{X}$ & 0.08623 & 0.08656 & 0.09522 & 0.09881 & 0.08437 & 0.09419 & 0.14254 & 0.13443 & 0.09326 & 0.09383 \\
\hline $9 \mathrm{Y}$ & 0.07355 & 0.0777 & 0.07536 & 0.07965 & 0.07616 & 0.0817 & 0.07257 & 0.07441 & 0.05834 & 0.06518 \\
\hline $10 \mathrm{X}$ & 0.26095 & 0.26635 & 0.25549 & 0.2614 & 0.26529 & 0.26247 & 0.27278 & 0.27154 & 0.29754 & 0.30203 \\
\hline $10 \mathrm{Y}$ & 0.17918 & 0.1741 & 0.20417 & 0.19853 & 0.18904 & 0.18408 & 0.20309 & 0.20219 & 0.18911 & 0.17937 \\
\hline $11 \mathrm{X}$ & 0.2352 & 0.23407 & 0.21112 & 0.2084 & 0.23457 & 0.22696 & 0.20349 & 0.20148 & 0.20567 & 0.20281 \\
\hline $11 \mathrm{Y}$ & 0.2464 & 0.23978 & 0.25139 & 0.24868 & 0.25621 & 0.25183 & 0.24767 & 0.24902 & 0.2491 & 0.2425 \\
\hline
\end{tabular}

Based on the positions of the groups in the PCA (Figure 2), it is clear that the species groups are well distinguished and that the main confusion among the groups is always between males and females of the same species. Although there is some superposition of the Plebeia remota and the Nannotrigona testaceicornis groups, it is easy to separate the species.

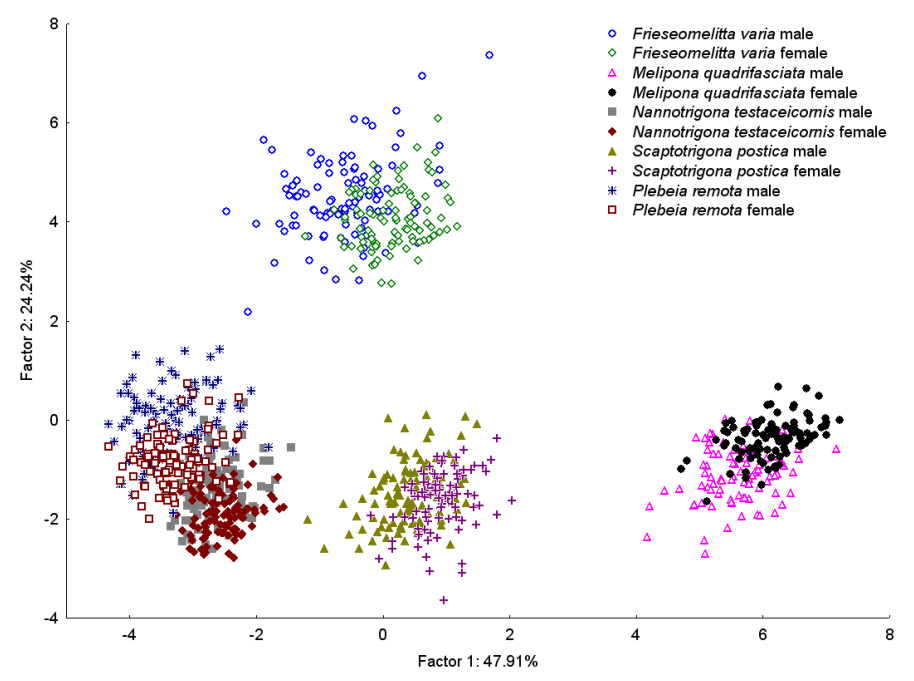

Figure 2. Scatterplot of the principal component analysis of males and females of the five stingless bee species analyzed. 
All the 18 partial warps that were extracted contributed significantly $(\alpha=0.05)$ to the separation of the 10 groups (males and workers of the five species). Multivariate analysis of variance (MANOVA) demonstrated that the groups were significantly different (Wilk's $\lambda=$ $0.000001 ; \mathrm{P}<0.0001$ ), and the cross validation test correctly classified $97.6 \%$ of the individuals to each respective group. The misidentifications were always between sexes in the same species and never among the species groups.

When analyzing only the males, all the 18 partial warps extracted contributed significantly $(\alpha=0.05)$ to the discrimination of the five species and MANOVA demonstrated that the groups were significantly different (Wilk's $\lambda=0.00002 ; \mathrm{P}<0.0001$ ). The cross validation test was able to correctly identify $100 \%$ of the individuals in each respective group using the equations generated in the discriminant analysis. All individuals were classified with a probability of between 99.99 and $100 \%$ of belonging to each respective group. The graphical distribution of the groups (Figure 3) was similar to the one obtained analyzing males and females together. Again, Nannotrigona testaceicornis and Plebeia remota were placed closer to each other than to the other groups, which were more isolated from each other. The Mahalanobis square distances between the groups are presented in Table 2 .

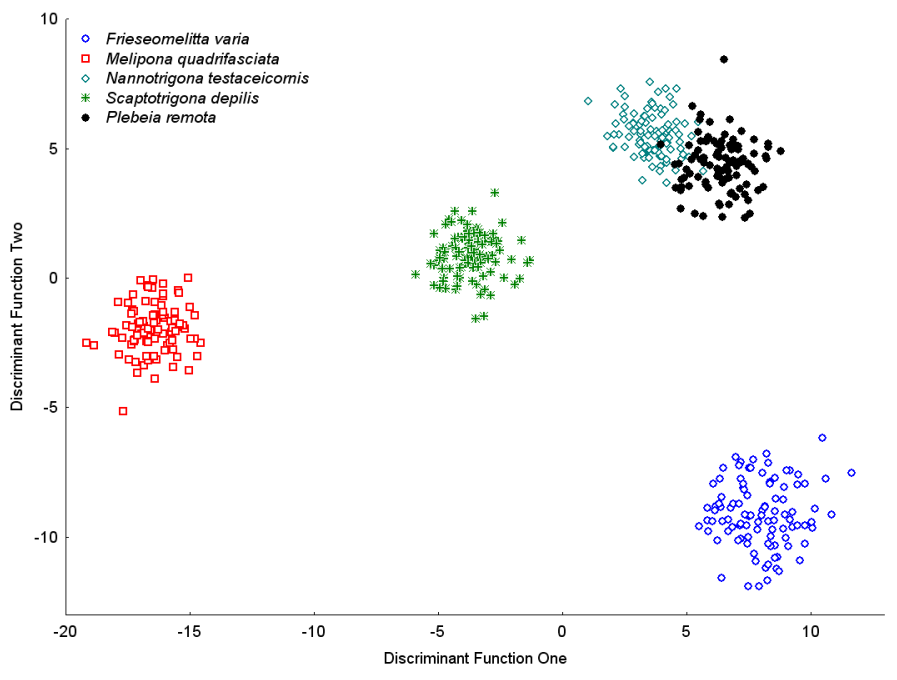

Figure 3. Linear discriminant analysis of the partial warps extracted from the wings of the males.

Table 2. Mahalanobis square distances between the centroid of the stingless bee group distributions.

\begin{tabular}{lccccc}
\hline & F. varia & M. quadrifasciata & N. testaceicornis & S. depilis & P. remota \\
\hline Frieseomelitta varia & - & 722.2968 & 345.86 & 333.3871 & 343.692 \\
Melipona quadrifasciata & 660.6635 & - & 663.2243 & 307.3305 & 812.7447 \\
Nannotrigona testaceicornis & 244.0675 & 483.1302 & - & 193.6911 & 59.18 \\
Scaptotrigona depilis & 258.0971 & 215.629 & 97.8428 & - & 316.7503 \\
Plebeia remota & 204.7816 & 574.6815 & 55.3284 & 174.2641 & - \\
\hline
\end{tabular}

The distances between the centroids of the worker distributions are in the upper right-hand triangle, and the distances between the centroids of the male distributions are in the lower left hand triangle. 
In the analysis of the workers alone, all the 18 partial warps contributed significantly $(\alpha=0.05)$ to the separation of the five groups. MANOVA demonstrated that the groups were significantly different (Wilk's $\lambda=0.000003 ; \mathrm{P}<0.00001$; Figure 4 ). The cross validation test of the workers was able to correctly identify $100 \%$ of the individuals in each respective group and all individuals were classified with a probability of $100 \%$. The graphical distribution of the groups was very similar to the one for the male analysis; again, workers of Plebeia remota and Nannotrigona testaceicornis were the closest two groups. The Mahalanobis square distances between the groups were greater for workers than for males (Table 2).

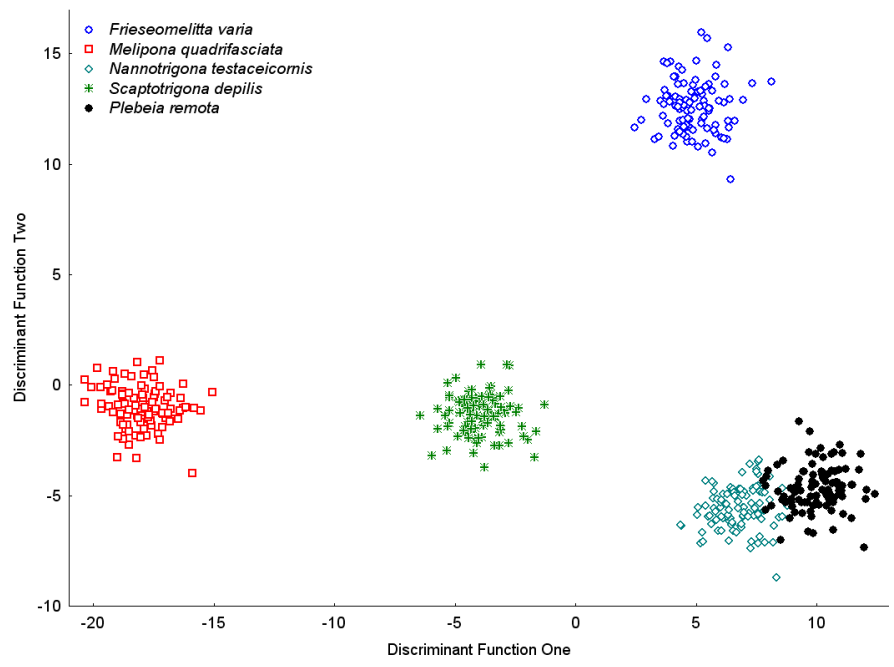

Figure 4. Linear discriminant analysis of the partial warps extracted from the wings of the females.

\section{DISCUSSION}

Though some insect species have large differences between the wings of males and workers, as in Apis mellifera, the wings of the different sexes of stingless bees are visually undistinguishable. A study made of four species of Eubazus (Villemant et al., 2007) showed that the patterns of wing venation between sexes in the same species are more closely related to each other than to specimens of the same sex in other species. We found the same pattern in our results. The functional role of the wing veins is not yet clear, and some authors even hypothesize that these patterns are not related to stability during flight at all, being related instead to the distribution of sensory receptors in the wings (Kammer, 1985). The only veins with known functionality are the leading edge veins, which are important for the stability of the wings during flight. Clustered or thickened veins in the leading edge of the wing are found in nearly all insects, even insects that have (evolutionarily) lost all other wing veins (some hymenopterans and small dipterans). According to Combes and Daniel (2003) the absence of these veins would lead to reduced stiffness of the wing and would compromise flight. We have also found that the features extracted from the wing venation patterns are very useful for dis- 
criminating stingless bee species. This fact is known for other bee groups, including Bombus, Andrena, Colletes, and Apis (Schröder et al., 1995; Steinhage et al., 2001; Drauschke et al., 2007; Francoy et al., 2006, 2008, 2009). We recently used wing venation patterns to distinguish subpopulations in a Nannotrigona testaceicornis population in southeast Brazil (Mendes et al., 2007) and found that information about the wing morphology of Plebeia remota can help discover new species, which was corroborated by other methodologies, such as mtDNA random fragment length polymorphism and cuticular hydrocarbons (Francisco et al., 2008). The association of morphology with other markers, such as molecular data, is very useful for discriminating bee species; joining information from these analyses can help identify stingless bee species and help us better understand their biology.

Features extracted from the wings of males and workers were very informative in discriminating the five species that we examined. If we take into consideration that the errors in the cross validation test happened only between sexes in the same species and never between species, this means that we can use either males or workers for species identification. We are now conducting studies to check if this is also true for bees from the same genus. This is the first time that several genera of stingless bees have been differentiated using geometric morphometry of wings. Even with the reduction of the wing veins in this group, these characteristics are sufficient to discriminate among the species.

\section{ACKNOWLEDGMENTS}

Research supported by CAPES, CNPq (Proc. 151947/2007-4) and FAPESP (Proc. 04/15801-0 and 06/60615-5).

\section{REFERENCES}

Aytekin AM, Terzo M, Rasmont P and Çagatay N (2007). Landmark based geometric morphometric analysis of wing shape in Sibiricobombus Vogt (Hymenoptera: Apidae: Bombus Latreille). Ann. Soc. Entomol. Fr. 43: 95-102.

Biesmeijer JC, Roberts SP, Reemer M, Ohlemuller R, et al. (2006). Parallel declines in pollinators and insect-pollinated plants in Britain and the Netherlands. Science 313: 351-354.

Combes SA and Daniel TL (2003). Flexural stiffness in insect wings. I. Scaling and the influence of wing venation. J. Exp. Biol. 206: 2979-2987.

Drauschke M, Steinhage V, Pogoda A, Müller S, et al. (2007). Reliable Biometrical Analysis in Biodiversity Information Systems. In: Proceedings of the 7th International Workshop on Pattern Recognition in Information Systems (Fred A and Jain AK, eds.). INSTICC (Institute for Systems and Technologies of Information, Control and Communication) Press, Funchal, 25-36.

Francisco FO, Nunes-Silva P, Francoy TM, Wittmann D, et al. (2008). Morphometrical, biochemical and molecular tools for assessing biodiversity. An example in Plebeia remota (Holmberg, 1903) (Apidae, Meliponini). Insect. Soc. 55: 231-237.

Francoy TM, Prado PPR, Goncalves LS, Costa LD, et al. (2006). Morphometric differences in a single wing cell can discriminate Apis mellifera racial types. Apidologie 37: 91-97.

Francoy TM, Wittmann D, Drauschke M, Müller S, et al. (2008). Identification of Africanized honey bees through wing morphometrics: two fast and efficient procedures. Apidologie 39: 488-494.

Francoy TM, Wittmann D, Steinhage V, Drauschke M, et al. (2009). Morphometric and genetic changes in a population of Apis mellifera after 34 years of Africanization. Genet. Mol. Res. 8: (in press).

Gaston KJ and O'Neill MA (2004). Automated species identification: why not? Philos. Trans. R. Soc. Lond B Biol. Sci. 359: 655-667.

Kammer AE (1985). Flying in Comprehensive Insect Physiology, Biochemistry and Pharmacology. In: Nervous System: Structure and Motor Function (Kerkut GA and Gilbert LI, eds.). Pergamon Press, Oxford, 491-552.

Mendes MFM, Francoy TM, Nunes-Silva P, Menezes C, et al. (2007). Intra-populational variability of Nannotrigona testaceicornes 
Lepeletier 1836 (Hymenoptera, Meliponini) using relative warps analysis. Biosci. J. 23 (Suppl 1): 147-152.

Rolhf FJ (2005a). tpsDig, version 2.04. Department of Ecology and Evolution, State University of New York, Stony Brook. Rolhf FJ (2005b). tpsRelw, version 2.04. Department of Ecology and Evolution, State University of New York, Stony Brook. Schröder S, Drescher W, Steinhage V and Kastenholz B (1995). An Automated Method for the Identification of Bee Species (Hymenoptera: Apoidea). In: Proc. Intern. Symp. on Conserving Europe's Bees. Int. Bee Research Ass. \& Linnean Society, London, 6-7.

StatSoft Inc. (2001). STATISTICA (data analysis software system). Version 6. Available at [www.statsoft.com]. Accessed November 15, 2008.

Steinhage V, Arbuckle T, Schröder S, Cremers AB, et al. (2001). ABIS: Automated Identification of Bee Species. In: BIOLOG Workshop, German Programme on Biodiversity and Global Change Status Report, Bonn, 194-195.

Steinhage V, Schröder S, Lampe KH and Cremers AB (2007). Automated Extraction and Analysis of Morphological Features for Species Identification. In: Automated Taxon Identification in Systematics: Theory, Approaches and Applications. The Systematics Association Special Volume Series 74 (MacLeod N, ed.). CRC Press, Taylor \& Francis Group, London, 8: 115-129.

Tofilski A (2004). DrawWing, a program for numerical description of insect wings. J. Insect Sci. 4: 17.

Villemant C, Simboloti G and Kenis M (2007). Discrimination of Eubazus (Hymenoptera, Braconidae) sibling species using geometric morphometrics analysis of wing venation. Syst. Entomol. 32: 625-634. 